Int. J. Electrochem. Sci., 15 (2020) 12599 - 12609

International Journal of

ELECTROCHEMICAL

SCIENCE

$\underline{\text { www.electrochemsci.org }}$

\title{
A Sensitive Electrochemical Sensor Based on Graphene/Pt Nanoparticles for Simultaneous Determination of Tyrosine and Tryptophan in the Presence of 5-hydroxytryptophan
}

\author{
Yingliang Wei ${ }^{*}$, Anting Wang, Lu Wang \\ Department of Environmental Engineering and Chemistry, Luoyang Institute of Science and \\ Technology, Luoyang, 471023, Henan Province, P. R. China \\ *E-mail: wei66720@126.com
}

doi: $10.20964 / 2020.12 .54$

Received: 29 January 2020 / Accepted: 11 September 2020 / Published: 31 October 2020

\begin{abstract}
A composite material, namely, graphene/ Pt nanoparticles (GR/PtNPs) was prepared in this work. This composite material was characterized by transmission electron microscopy (TEM) and Fourier transform infrared spectroscopy (FTIR). Based on GR/PtNPs modifed glassy carbon electrode (GR/ PtNPs/GCE), a sensitive and simple sensor was developed for simultaneous measurement of tryptophan (Trp) and tyrosine (Tyr) in the presence of 5-hydroxytryptophan(5-HTP). Under optimized measurement conditions, the oxidation peak current of Tyr increased linearly within a concentration range from $5.0 \times 10^{-7}$ to $2.0 \times 10^{-5} \mathrm{~mol} / \mathrm{L}$ with a detection limit of $1.25 \times 10^{-7} \mathrm{~mol} / \mathrm{L}$. The linear response of Trp was also obtained in the range from $2.0 \times 10^{-7}$ to $1.2 \times 10^{-5} \mathrm{~mol} / \mathrm{L}$, and the detection limit was $8.22 \times 10^{-8} \mathrm{~mol} / \mathrm{L}$. When Tyr and Trp samples were measured, the recovery rate of tyrosine was $98.4 \%$ to $103.5 \%$, and the recovery rate of tryptophan was $98.7 \%$ to $102.9 \%$, which indicates that the accuracy of GR/PtNPs/GCE was high. Additionally, the GR/ PtNPs/GCE demonstrated suitable selectivity for the determination of tryptophan (Trp) and tyrosine (Tyr), making it practicable for their measurement of Trp and Tyr in pharmaceutical formulations.
\end{abstract}

Keywords: Graphene; Sodium polystyrene sulfonate; Pt nanoparticles; Tyrosine; Tryptophan

\section{FULL TEXT}

(C) 2020 The Authors. Published by ESG (www.electrochemsci.org). This article is an open access article distributed under the terms and conditions of the Creative Commons Attribution license (http://creativecommons.org/licenses/by/4.0/). 